\title{
An Analytic Approach to Culture ${ }^{1}$
}

\author{
Omar Lizardo ${ }^{2}$
}

${ }^{1}$ Draft chapter prepared for The Architecture of the Social edited by Peter Hedstrom and Petri Ylikoski.

2 Department of Sociology, University of Notre Dame, 810 Flanner Hall, Notre Dame, IN, 46556. Email: olizardo@nd.edu, Tel: (574)631-1855. 


\section{Introduction}

\subsection{Explanation in Cultural Analysis}

While the issue of the nature of social explanation is a contested one in the study of cultural phenomena (e.g. Reed 2011), an analytic approach in cultural analysis should not be neutral or unsystematically eclectic as to what counts as an explanation. From an analytic perspective, a phenomenon cannot be said to have been explained until the relevant micro and meso processes (mechanisms) as they are arranged in a given (sometimes bounded) context into a generative interactive system have been specified (Bechtel and Abrahamsen 2005; Bunge 1997; Machamer, Darden, and Craver 2000). The key epistemic goal is to describe how the target phenomenon in question is reliably realized via the operation of the set of mechanisms and associated activities within the bounds of the interactive system at hand. This requires both the specification of the phenomenon (independently from any data that we may bring to bear (Woodward 2011)) as well as the targeted search for generative mechanisms that may be responsible for it (Hedström and Ylikoski 2010). In social science, the relevant interactive systems in which most relevant cultural phenomena are produced comprise multiple mereological levels, ranging from the cognitive, interactive, group, organizational, inter-institutional and global (Jepperson and Meyer 2011).

Just like other social phenomena, cultural phenomena are generated in multilevel systems of interacting mechanisms (Thagard 2014). Drawing on Bunge (2004), I define an interactive system as a quadruple <Environment, Parts, Interconnections, and Change $>$ (EPIC). When dealing with cultural processes responsible for the generation of important phenomena, such interactive systems are the proper unit of analysis; and may be referred to as dynamic cultural causal systems (DCCS). These are composed of (a) persons, (b) cultural elements internalized by persons, (c) social relations between persons, (d) external cultural symbols and artifacts mediating the process of cultural expression and transmission among persons. Note the ubiquity of persons across all four components. A given DCCS may thus be composed of a 
variety of mechanisms at multiple mereological levels. Sets of mechanisms form a hierarchy going from the most "micro" (which at the current state of the cognitive social sciences may involve neuro-cognitive processes) to the most "macro" (e.g. directly intervening between the macro-cause and the macro-effect). In this way, a more concerted focus on interactive systems and generative mechanisms can help cultural analysts in two crucial tasks for coming up with effective explanations of cultural phenomena: localization and decomposition (Bechtel and Richardson 2010).

\subsection{Localization and Decomposition in Cultural Analysis}

The, identification of generative mechanisms in DCCSs can help us in localizing cultural phenomena. This has been a perennial problem (and source of criticism) of cultural theories in sociology, beginning with classic functionalism (Lizardo 2016a). This tradition has conceptualized "culture" as if it was in Gary Alan Fine's (Fine 1979, 733) memorable words "an amorphous, indescribable mist which swirls around society members." Two decades later, Ann Swidler (2000) echoed the same sentiment, noting that culture continued to be treated as some "mist" that envelops persons and contexts, is both everywhere and nowhere but which also somehow manages (somehow) to get inside persons and influence their action. Most cultural theorists understand the problems that beset this conceptualization of culture, but solutions to it have been harder to come by (Ghaziani 2009).

Second, a focus on mechanisms can help us in decomposing cultural phenomena. The notion (and desirability) of decomposition in cultural analysis (and social explanation more generally) may initially seem controversial and thus harder to defend. The reason for this is that, in some corners of social science, decomposition is likely to be mistaken for the notion of reduction. This can be a particularly touchy topic for cultural sociologists, as cultural analysis first opened up a niche in the discipline precisely by promoting higher levels of analysis and fending off various materialisms, reductionisms, and individualisms (J. Alexander 1992). 
But decomposition is not reduction; in fact decomposition is fairly compatible with a view of the properties of macro-phenomena as emergent and not reducible to the properties exhibited by their lower level components (Bunge 2004). Decomposition is a well-established (and pragmatically justifiable) heuristic strategy in many scientific fields concerned with the characterization of complex, multi-level systems, of which DCCSs are an example (Bechtel and Richardson 2010). In addition, an emphasis on decomposition is important, because unwieldy, ontologically unmoored, macro-abstractions are prone to run rampant in the field (Lizardo 2016a). Precisely because culture is usually mistaken for (or enthusiastically portrayed as) a delocalized, immaterial abstraction (Biernacki 2000), following the heuristic strategies of localization and decomposition focusing strongly on the effective characterization of macro-phenomena can do a lot to strengthen cultural analysis.

\section{Reconceptualizing Culture}

\subsection{Beyond Culture-as-Entity}

Just like an analytic approach is not neutral as to the question of what counts as an explanation in cultural analysis, it is also not neutral as to the question of what culture is in the first place. The reason for this is that there are conceptions of the nature culture that reject the localization and decomposition assumptions; these conceptions of culture are obviously incompatible with an analytic explanatory program. One of the most influential anti-analytic conceptions of culture is one that defines as (complex) holistic entity partially decoupled from persons (Kuper 2009). As we saw earlier, when conceptualized as a holistic entity culture loses the localizability criterion; instead either culture devolves into an invisible "mist" located everywhere and nowhere (Fine 1979). Alternatively, analysts are forced to conceptualize the "location" of culture as living in some ontologically unmoored (due to the dualism between material and ideal embedded in this conception) "cultural realm" hovering above the empirical world (Lizardo 2016a). 
Thankfully, the premise that culture is not such a (holistic) "entity" is a fundamental point of departure of the most influential recent strands of contemporary cultural analysis in sociology (DiMaggio 1997; Patterson 2014; Sewell 2005; Swidler 2001). The rejection of the "Herderian" model of "cultures" as holistic entities is a healthy development since, as already noted, a mechanismic program of analysis requires that the target object of inquiry be both localizable and decomposable. Quasi-organicist models of culture as holistic entities linked to "peoples" put insurmountable roadblocks against both analytic strategies, and trade on "folk" meanings of the culture concept not usable for scientific purposes (Goddard 2005/1). In fact, the residual impact of Herderian models of culture as coherent wholes linked to "peoples" may be to blame for the rather underdeveloped state of "analytical" approaches in cultural analysis compared to other domains in the social and behavioral sciences (Patterson 2014).

As noted by Sewell (2005) Herderian holistic models import a "folk" definition of "cultures" as unique meaning complexes characteristic of a "people," so we might speak of "Chinese Culture," "Navajo Culture" or even "Western Culture." Second, they collapse the ideational aspects of culture with such ethnosomatic, ethnoreligious, ethnonationalist, or ethnogeographical identifiers so that the analytical aspects of the culture concept (culture as a category of analysis) become fused with the pragmatic uses of the term for the constitution, definition, differentiation, and competition among social groups (culture as a category of practice). Note that the holistic approach spuriously "solves" analytically what is in fact an empirical issue, namely that of the degree of "sharedness" of culture, from the start (this it shares with the folk conception of culture; see Goddard 2005: 57). Herderian approaches do this by presupposing (rather than empirically investigating) such sharedness.

I propose, with Sewell (2005), that the analytical concept of culture should be kept distinct from the folk concept, since the latter is not useful for an analytic (or any scientific) program. An easy linguistic test useful for distinguishing the two concepts in any argument is that if the term culture as used in a way that partakes of grammatical constructions capable 
of pluralization (e.g. culture as a "count noun") so that the analyst can speak of "cultures" or in way that requires a qualifier referring to a group (e.g. "Chicano culture") then that is probably the folk conception (for a detailed, and illuminating, exploration of the folk conception of culture from the point of view of lexical semantics see Goddard 2005). The analytical concept of culture is instead a "mass" noun (thus not capable of being pluralized), and rather than pointing to a "group" of people, it refers to a property of some ontologically real set of entities, internalized, used by, or somehow represented in or by persons. Note however, that is we follow a fully decompositional strategy (as I will argue in what follows) and find "elements" of culture at lower mereological level, then these elements can be pluralized without analytical loss (e.g. "schemata", “associations”).

Why then is the conception of culture as holistic entity so hard to shake off? I suspect that cultural theorists hold on to Herderian models of culture as entity because they see this as the only way to theorize culture as having independent causal powers not "reducible" to the causal power of other "non-cultural" entities and processes (Ignatow 2014). A key claim I will try to defend here is that we can theorize culture as composed of elements which, when suitable internalized or used by persons, may act, via persons as powerful particulars (Varela and Harré 1996), in causally relevant ways. However, it is both undesirable and inconsistent with an analytic approach to posit that a holistic, non-material entity designated as "culture" acts as a causal agent in its own right (Kitayama 2002, 92). Recent work from a critical realist perspective is ambiguous in this respect (e.g. Elder-Vass 2012), as it sometimes deploys arguments "for" emergence as a blank check to fall back on entitative arguments of culture as a complex whole exercising (non-mechanismic) direct effects via “downward" causation (see also Jepperson and Meyer 2011).

A key conceptual roadblock here concerns certain limitations (embedded in the theoretical imagination of cultural analysts) regarding what "holds" culture together. Note that even the posing of this question already presupposes some at least partially "analytic" (decompositional) approach as only a "whole" that is made up of parts can be said to be "held 
together" (by links or relations among the parts; see e.g. Elder-Vass 2007; Lizardo 2013). My argument (following D'andrade 2001) is that it is perfectly possible to conceive of culture as a non-entitative collection (not a holistic entity), so that nothing in fact "holds it together" (other than the co-presence of a persons in an interactive system) and still speak coherently of culture's emergent causal powers (when internalized by persons). This however, will require getting clear on the knotty issue of endogenous "relations" between cultural elements.

\subsection{Re-conceptualizing Cultural Relations}

It is important to distinguish two different ways in which cultural elements may be related to one another and thus ultimately two ways to think of culture as a hierarchically arranged "system" (without falling into neo-organicist traps of culture-as-entity).

\subsubsection{Internal Cultural Relations}

As noted by most "realist" cultural analysts (e.g. Archer 1996), cultural "wholes" may be held together by internal set of relations that are specifically "cultural" or "internal" to culture. There is an inevitable circularity that besets this formulation, but the reader will have to bear with me on this, since the circularity cannot be eliminated until we take a stronger position on the mechanisms via which elements of culture link up to one another and what the nature of these elements are. These "internal" relations, as noted by cultural analysts steeped in the Saussurean semiotic tradition may be "synchronic" and need not "play out" temporally (Giddens 1979).

For instance, in standard structuralist approaches to cultural analysis these internal cultural relations may be sequential contiguity in a linear chain ("syntagmatic") or ones of substitutability in a limited space of alternatives ("paradigmatic"; see e.g. Saussure (1964)). Archer (1996), inspired by earlier work by Pitirim Sorokin on cultural dynamics and Karl Popper on truth-conditional semantics, also proposes a conception of internal links that hold

cultural systems together; these link propositions playing the role of cultural units (living in a 
purely impersonal world of all possible intensional meanings; Popper's "World III") via logical relations of implication (which may or may not be realized empirically in the mind of persons).

\subsubsection{External Cultural Relations}

The other relation that analysts see as linking cultural elements are causal and "external" to culture when conceived as a systematic whole. These relations play out in time, involving processes of social interaction, "socio-cultural interaction, institutionalization, learning, objectification, transmission, and reproduction (Archer 1996; Berger and Luckmann 1966). These causal links between cultural elements are usually seen as a delimited a realm of cultural interplay and causation that is "exogenous" (or at least should be distinguished from) processes of cultural change that rely primarily on "endogenous" relations between cultural elements (Kaufman 2004; Obukhova, Zuckerman, and Zhang 2014).

\subsubsection{Two Kinds of Cultural Wholes}

The distinction between two ways in which cultural elements may be related to one another (e.g. synchronic, "endogenous" non-causal relations and diachronic, "exogenous" causal relations) leads to two ideal typical ways of conceiving of cultural "wholes," either as (static) cultural structures or (dynamic) cultural causal systems. My proposal is that the notion of "cultural structure" is both analytically incoherent and inconsistent with a mechanismic

program of analysis, while the notion of cultural causal system is consistent with such a program (Bunge 2004; Kitayama 2002).

This is not because a mechanismic program is necessarily hostile to the idea that cultural elements may be related by non-causal relations to form higher order "chunks" or "packets" of meaning. Instead, what I argue is that there are no "cultural wholes" of the sort that exist "outside of the mind" of persons composed of non-material elements united by implication, contrastive or other sort of "meaningful" relations. My proposal is that most of what are usually referred to as "internal" relations between cultural elements resolve 
themselves into cognitive relations of "meaning compression" in higher orders structures (e.g. scripts, schemata, mental models) specific to domains of experience or activity primarily internalized by persons as a result of a learning process (Strauss and Quinn 1997) and secondarily expressed by persons as a result of processes of symbolization (Lizardo 2016b). The key point is that there is no evidence that the totality of knowledge across domains itself make up an overarching cultural organism with high levels of integration as Parsons (1951)or Geertz (1973) would have it. Instead, knowledge across meaning packets is largely dissociated (Lizardo 2017), and in most large-scale human populations this knowledge is distributed across persons so that no one person can be said to have internalized the totality of the potential culture (Reay 2010).

\subsubsection{Defining Culture (and the Cultural)}

How can culture be defined from an analytic perspective? The problem here is once again one of ontology: Culture is not a nonmaterial entity hovering outside (or above) the material world; therefore culture cannot be defined as partaking of the sort of unity that entitative theorists assign to it (Swidler 2001). As alluded to above, a mechanismic approach suggests that culture is not an entity at all, although in some delimited uses it may refer (in a non-interesting, non-analytic way to a collection of lower order elements). Culture is instead a quality of certain cognitive elements defined by a genetic criterion (that the cognitive element emerged from either a process of learning or combination of learned elements) and that it be shared (e.g. that there be at least one other person who also has learned or independently generated that element from a combination of similar elements). A given cultural element or higher order packet of such elements is "cultural" if it is both learned (and learnable) and shared at a point in time.

Thus, the approach I take to the entitativity of culture may be broadly referred to as “cognitivist” (D’andrade 2001; Gatewood 2001; Sperber 1996), as I see this approach as the most compatible with a mechanismic program. This means that the "internal" relations 
among cultural elements of traditional cultural theory are not posited as those existing between non-material elements in a non-material cultural realm, but between (localized and decomposable) cognitive routines and structures within persons. Cultural elements are related within persons and a relation between cultural elements may be said to be cultural when the same relation can be found within more than one person. This is the view of "culture" that has been implicit in modern (cognitive) personality and social psychology and cognitive anthropology since at least the 1970s. For instance, the relation between "Black Man" (as a cultural unit pointing to a category of person defined both gender and ethnosomatic markers) and "violent" (as a cultural unit pointing to the qualities of certain actions) is a really existing cultural relation among cultural elements within large swaths of persons in the U.S. (Nosek, Banaji, and Greenwald 2010). Accordingly, a model of spreading activation in a neural network does a good job of accounting for the results of stereotype research governed by this cultural syndrome (Schröder and Thagard 2013).

From a cognitivist perspective, culture is just such a shared set of cultural units (at different levels of aggregation from the simple to the more complex) and a shared set of relations among these elements within a, usually arbitrarily delimited, "population" of persons. Because there are no "cultures" that are co-extensive with a "people" (in contrast to the Herderian model), the delimitation of a population is always arbitrary (Gatewood 2001, 228) as is the delimitation of the set of elements to be considered as part of the culture (Biernacki 2000). Depending on the cultural element or the relation among elements we choose, we can find so-called "universal" cultural elements (e.g. the abstract concept of noun) and "universal" relations between elements (e.g. "anger is hot") which point to "humanity" as the population or question (Kövecses 2003). Alternatively, if we may pick an idiosyncratic set of elements (e.g. those making up a particular cargo cult) such that the population under consideration becomes severely restricted. Note however, that this only implies that such a set of people are "different" with respect to the arbitrarily chosen idiosyncratic elements but not in relation to the (infinitely larger set) of elements (e.g. the 
belief that trees have green leaves) they share with the rest of the human population (D'andrade 2001, 255-257).

A key implication of the cognitivist approach is that organicist cultural structures, existing outside of the head of persons, or containing more "information" (either in terms of number of elements or relations between them) that can be found in the distributed knowledge of a set of agents at a time (of the sort envisioned in either organicist-functionalist or semiotic-structuralist cultural theories) do not exist. What exist are distributed cultural elements and relations, characterized by structured "packing" or "chunking" of relations among designated elements organized by either psycho-biological domains (e.g. plants, animals, number) or by social-institutional domain (e.g. sociology, law, religion). The sum total of all cultural units and relations are "held" in no single person's head, although persons in proximity and in regular interaction will (via the endogenous and exogenous mechanisms of cultural transmission) come to "share" (some of) these elements.

Cultural analysts (especially in sociology) are not interested in domains sharing "cultural structure" as a self-delimited domain of experience or activity (e.g. in the way that an anthropologist may be interested in the ethnobotany of a culture area). Instead, social scientists are usually interested in the study of cultural causal systems made up by the complex interplay (at multiple analytic levels) between endogenous cultural processes and exogenous social, interactional, and institutional mechanisms that ensure either cultural reproduction or change. From a mechanismic perspective thus, it is not the ghostly immaterial (and spurious) cultural structure that is the unit of analysis, but the dynamic cultural causal system, composed of persons, their relations, externalized cultural symbols, and cultural artifacts as well as mechanisms of cultural generation, preservation, and transmission that matters.

An analytic approach also provides a substantively grounded conception of how the "internal" (or specifically cultural) relations among cultural elements may be conceptualized. Cultural theory whether in its functionalist, (Parsons 1951) structuralist-semiotic (J. C. 
Alexander 2003), social-phenomenological (Berger and Luckmann 1966), or even "realist" (Archer 1996) guises has struggled with this issue. This is because, following the misguided notion of cultural structures as neo-organicist holes subsisting in an ontologically unmoored "ideational" realm, it has also attempted to conceptualize endogenous cultural relations as impersonal connections between cultural elements, or at least as relations that do not involve persons a strong sense for their realization.

This approach is both incoherent and misguided (Smith 2011). First, cultural relations can never be "impersonal" in the strong sense of "ideo-realism" (either Platonic or Fregean), whereby culture exists independently of people. Instead, these relations are localized in persons, and are best conceptualized as "cognitive" (or more accurately neural) connections between elements as these are theorized in connectionist or spreading activation approaches to cultural learning and memory (M. Bloch 2012; Strauss and Quinn 1997). Some of these connections are "hardwired" or over-determined to be generated (and thus facilitated) in early experience, making them good candidates for cultural universals, while others depend wholly on time and place specific processes of learning, transmission, and experience and are thus "conventional," although not necessarily "arbitrary" in the semiotic sense (Cohen and Leung 2009).

From a cognitivist point of view, both the elements of culture (as dispositional knowledge about the world carried by persons) and the relation between these elements (as realized Hebbian connections between the neural structures instantiating the different elements) are real (exist in time and space within persons) and wholly localizable (in the neuropsychological sense). Note that localizability does not entail discreteness as most cultural elements and their interrelations are realized as either distributed neural structures instantiated in dynamically assembled, experience-sensitive neural systems within persons (Anderson 2014), or as distributed knowledge structures (themselves composed of distributed neural structures) across persons (Hutchins 1995). Arbitrarily delimited "cultures" (as collections not entities) thus comprise the social distribution of these distributed neural structures (coding for both cultural 
units and their relations) in interaction with the sensuous objectifications of these meanings in cultural symbols and artifacts (Lizardo 2016b).

This leads to a workable definition of culture useful for analytic work:

Noun: A shared set of cognitive elements (at different levels of compositionality from the simple to the more complex) and most importantly a shared set of relations among these elements within a, usually arbitrarily delimited, "population." Because there are no bounded "cultures" that are co-extensive with a "people" (as in the Herderian model), and there are no cultural elements that necessarily hang together into a coherent whole outside of the mind-brain (as in the entitative model), the delimitation of both the relevant set of relations as well as the population to which these relations are imputed always carries a degree of arbitrariness and therefore is an analytic decision.

Note that this definition complies with both the localizability and decomposition criteria. Cultural elements as cognitive structures and processes are localized in (suitably encultured) persons. Cultural elements are thus "neurocognitive" because cognitive structures are realized as distribution of within-person structures and relations (e.g. associations) between these structures. The localization relation is nested in the sense that encultured persons (as "carriers" of culture) are themselves localized in concrete interactive contexts, which leads to the notion of culture as a distribution of knowledge (Berger and Luckmann 1966; Hutchins 1995; Reay 2010). Because the localization relation is transitive, it can be said that "culture" itself is localizable in those contexts, although the analyst needs to be careful to never talk about the localization of culture in the absence of persons (and their interactions). As such, an analytic approach to culture moves beyond obsolete debates as to the primacy of "culture" versus "structure," as this debate is premised on an entitative view of culture as a whole that is subject to the causal force of another (equally spurious and, even worse, residual) "structural" whole (Hays 1994).

\subsubsection{The Primacy of Persons in Cultural Analysis}

The traditional "culture versus structure" approach also flounders in ignoring the 
crucial premise that "culture" never enters into causal relations with other entities absent the mediation of persons are powerful particulars (Varela and Harré 1996). It is persons who engage in cultural recombination (e.g. reshuffling cultural elements into novel ones), it is persons who express meanings in the form of cultural symbols, it is persons who communicate, it is persons who internalize culture via learning processes, it is persons who reconstruct cultural elements acquired via this learning history (Smith 2011). The main cultural phenomena (e.g. cultural change) are generated via the intermediation of persons in specific interactive contexts. As such, culture by itself (as a collection or distribution) lacks causal powers. Although culture can produce causal effects by transforming the powers and capacities of persons who then transmit those effects to the world. In this respect, culture enters into causal relations with things that are not culture, only when persons are located in concrete dynamic cultural causal systems.. However, cause effect relations are always between specific cultural elements (at different levels of compositionality) and specific structures and processes and not between culture as a "whole" and some other set of entities.

Given this, we can also define the property of a set of neurocognitive elements as being "cultural":

Adjective: A quality applicable to a set of cultural elements (at different levels of compositionality from the simple to the more complex) and most importantly a shared set of relations among these elements, by virtue of being both learned and/or shared across persons.

\section{The Units of Culture: An End to the Debate?}

As we have seen, traditional approaches to explaining the dynamics of cultural change and reproduction in cultural analysis suffer from fatal analytic limitations. While holistic approaches to cultural dynamics (e.g. those favoured by Sorokin or classic "civilizational" analysis) are no longer in favor, and while most cultural analysts agree that some (either partial or full) decomposition of cultural wholes into constituent elements is required for proper explanation, there is not much in the way of an useful analytic framework for the 
study of cultural change and reproduction as a complex multilevel phenomenon. One important reason for this is that a decompositional strategy requires agreement on what the whole is being decomposed into. Cultural theorists however, have been particularly reluctant (perhaps due to the perennial fear that decomposition implies reductionism) in theorizing the mereology of cultural phenomena. While a lot of attention has been paid to theorizing the cultural "whole" and its alleged properties (e.g. systematicity) little attention has been paid to theorizing the cultural "parts." Yet, a mechanismic approach to cultural dynamics requires that we get clear about what the fundamental "cultural parts" partially constitutive of larger-scale cultural phenomena are (D'andrade 2001)

I draw on recent work in cultural and cognitive sociology and cognitive anthropology to tackle the problem of cultural units head on. I argue that the "conceptualized object" (or a "conceptualization" in Lagacker's 1987 terms) is a viable candidate for serving as a "culture unit" and that a (fully) decompositional strategy can be workable taking by this as the underlying component of more complex cultural causal systems (which as we saw above also include persons, objects, and their interactions).

Such an approach has a series of important implications for cultural analysis. First, it commits the analyst to an ideational view of culture (Archer 1996; Parsons 1938), since conceptualizations are primarily mental phenomena. That said, an ideational view of culture does not imply a (largely discredited) "dualism" of the ideal versus the material (Sperber 1996). Instead, consistent with the consensus in contemporary philosophy of mind (McCauley and Bechtel 2001), conceiving of "culture units" are mental phenomena is perfectly compatible with an identity theory of brain and the mind, in which mental phenomena are realized (and thus seen as type-identical) in localizable (and themselves decomposable) neural-phenomena in the brain (Anderson 2014). Culture-units are thus localizable and decomposable in the same way, although the decomposition of interest to the cultural analyst is likely to be "semantic" (Hjelmslev 1961, 69-75) rather than neurophysiological. This is an approach with a long pedigree in linguistic, social, and cultural 
anthropology, prototypically exemplified in the "componential analysis" (also referred to as "lexical decomposition" and "semantic feature analysis") of kinship and related terms (D'Andrade 1995: 30). The difference between the approach proposed here, and classic componential analysis is that rather than proposing abstract (and ultimately arbitrary because analyst imposed) "features" as the underlying components of cultural elements, I propose that conceptualizations resolve themselves into a set of cognitive routines responsible for their instantiation in concrete situations (Langacker 1987).

In this sense, from an analytic perspective, recent attempts to divide culture into "personal" and "public" kinds are making both an ontological and analytical point. Culture units typically have (as encountered by persons) "sensuous" (so-called "material") manifestations (Lizardo 2016b). However, having a sensuous manifestation is not an inherent property of culture units as mental entities. For instance, this would prevent shared conceptions that are never objectified in spoken or written language or in material symbols rituals or artifacts from cultural status, which is undesirable. Instead, culture-units as inherent carriers of cognitive meaning are conjoined with material manifestations only when persons wish to objectify these meanings either for expression or communication. The generation of cultural symbols presupposes the "pre-existence" of the semantic (cognitive meaning) pole of the symbol, which in the terms offered here simply refer to the ideational cultural unit in question.

Yet, in contrast to overstated claim in the symbolist tradition of cultural analysis, the nature of culture is neither inherently sensuous nor material (in the naïve sense), although it is the nature of the cultural symbol to be a bipolar joining (or fusion) of mental content and physical structure (Lizardo 2016b). However, the underlying nature of culture from an analytic perspective is conceptual, since it is possible for persons (and non-human animals) to have and use culture even when they do not have access to cultural symbols. However, the fusion of conceptual content and material form (in the shape of "cultural symbols") enhances the causal power of culture by facilitating the mechanism of cultural transmission 
in dynamic cultural causal systems. This assigns the property "cultural" to several elements that would otherwise "fail" to gain this character. The fusion of cognitive meaning and material form constitutive of the "cultural symbol," is required for persons to either externalize (for themselves or others) or communicate cultural meanings during processes of cultural expression or transmission, but nature of culture is cognitive not "symbolic."

In defining the "units" of culture as conceptualized objects (conceptualizations) is important to realize that I am using the word "object" here in its most general (phenomenological) sense. Thus, while a physical table is not a conceptualization (and thus not a unit of culture), a conceptualized table is (L. Barsalou 2003). Even if all the physical tables in the world were to be destroyed tomorrow, the cultural-unit "table" would remain internalized in persons or objectified in material artifacts such as pictures, and IKEA furniture assembly instructions. These cultural-units could then be used by persons as a "model for" (Geertz 1973) constructing new tables. Note that the same argument applies to all culture-units including those conceptualizing "institutional objects" such as money, promises, marriages, and so on (Searle 1995).

Note also that objects need not be limited either to material entities with "extension" nor are they limited to the "basic level" objects that form the prototype for the category. Thus, the basic underlying source of cultural units are the basic human cognitive capacities, of which the most important one is the capacity for conceptual reification in which much anything (including processes that occur in time and atemporal relations between other conceptualized objects and abstract qualities and states) can be made into an object of conceptualization (Langacker 1987). This means that the number of potential objects of experience and "reference" (and thus capable of gaining cultural unit status) is open ended and is not delimited or "closed" by the total of physical qualities to which we persons are sensitive nor by the total of artifacts or basic-level material objects existing at any one time. In this sense, the capacity for conceptual reification is a basic input to the constitution of cultural objects even when these present themselves as "slices of experience" that do not 
have unambiguous perceptual boundaries (e.g. mountains, rivers, etc.); as these can still be made into "objects" of conceptualization (Berger and Luckmann 1966).

The basic organization of cultural units is mereological in the sense that a conceptualization is itself composed of other lower levels conceptualizations and ultimately basic perceptual cognitive routines (e.g. capacity to detect vertical and horizontal edges in medium sized objects). To take an example from cognitive linguistics, an "arm" (as a conceptualization) can be (and routinely is) thought of as containing other "lower level" conceptualizations arranged in a mereological hierarchy such as forearms, hands, knuckles, nails, and so so on (Langacker 1987). This conceptual mereology determines the sort of grammatical constructions that seem intuitive and thus come to be sanctioned by convention. This also means that there are culture units ("primitive" conceptualizations) that are more "basic" than others (because they partially cross-cut all other conceptions) and that are found as constituents of more complex conceptualizations (D'andrade 2001). A good candidate for primitive cultural units are the "image schemas" of cognitive semantics (Johnson 2013).

A good number of conceptualizations do not have a "real world" extension. These non-extensional conceptualizations can be thought of as being at the opposite pole of the conceptualizations for which capacities for reification in the human conceptual system contribute but do not completely determine unit status (Barsalou 2003). Thus, when a "rabbit" emerges as a conceptualization, both the world (in providing a relatively coherent set of qualities that hang together as a furry, long-eared critter) and the human conceptual system contribute to the constitution of that object as a conceptualization (L. W. Barsalou 1992). Because of the non-negligible contribution of the world, it is therefore unlikely, in the case of a rabbit, that we would observe "wild" cross-cultural variation in the constitution of the coherent slice of experience provided by rabbits (and thus a potential unit of culture). Essentially every human group that has been exposed to rabbits has developed a rabbit conceptualization, and has come up with a conventionalized lexical item in language to evoke 
that conception, associated with pretty similar set of properties.

In contrast to objects in which there is an equal input from the world and the human conceptual system, when generating such abstract conceptualizations as "liberty," or "ghosts" or "mana" the human conceptual system does most of the work of "constitution" into a culture unit (Barsalou 2003). These cultural units are much more likely to exhibit large cross-spatial and historical variation within and across populations (Maurice Bloch 1986), although, once again, this variation is unlikely (e.g. in the case of conceptualizations of supernatural entities to be truly "wild" (Barrett 2000)). In this last sense, these culture units depend on more basic (experience-near) ones for their overall conceptualization, and therefore will share underlying conceptual structure across populations (M. Bloch 2012). For instance, it is now well established that abstract (non-extensional) conceptualizations recruit conceptual resources (via metaphorical projection) from extensional conceptualizations grounded in direct experience but not the other way around (Lakoff 1993). This lends all cultural conceptions systematically shared structure preventing the (idealist) nightmare of radical problems of cross-cultural "translation" (Wierzbicka 1992). Finally, it is important to note that the construction of cultural units via conceptual reification may be applied to both relations (among previously constituted conceptualizations) and processes, such that both reified connections between qualities and objects may themselves become conceptualized objects and culture units in their own right (e.g. "blueness") as can processes extended in time but conceptualized as a unit-object ("explosions").

More complex conceptualizations, such as those that feature in theories that conceive of the units of culture at the level of entire "propositions" such as Archer's (1996), emerge from the integration of object conceptualizations into both static (atemporal) and dynamic (temporal) relations. In cognitive grammar (e.g. Langacker 1987) this is the mechanism of predication and is the primary way in which lower level conceptualizations are used (building block style) to generate more complex ones. Thus, the conceptualization "The cat is black." Links the cat unit object with the "black" unit object in an atemporal 
("adjectival") relation to produce a potential complex culture unit involving a propositional predication. The same goes for complex conceptualization "the cat jumped over the fence" which links a static (e.g. prepositional relationship ("cat over the fence") with a completed temporal process ("jumped") to conceptualize a state of affairs involving an actor (cat) a landmark (fence) a static relationship between the actor the landmark (cat over the fence) and a temporal relationship between the actor and a process (cat jumped). Such a unit may become "cultural" if for instance, it becomes generalized ("cats jump over fences") and transmitted regularly from generation to generation.

The advantage of this approach to the constitution of (potential) cultural units is the analytic promise for a fully decompositional, fully hierarchical approach to cognitive meaning. This is a key desideratum of an analytic approach (for more details on this type of "constructional" approach to language and conceptualization see Langacker 1987). The process of combination and recombination of more elaborate cultural units from lower level units, lends mereological (part-whole) complexity to most culture units, as well as serving as the ground of most cultural genesis via processes of meaning construction.

The most important form of meaning construction consists in the (novel) integration of older conventionalized units into more complex ones (Coulson 2001). Thus the conceptualization "gray shark" emerges from the atemporal relation between the conceptualization for shark and the conceptualization for "gray" (the conceptual reification of a given slice of the color continuum) and their juxtaposition in an atemporal relation (L. Barsalou 2003). This conceptualization is now available to enter into higher order relations with other conceptualizations in which the new complex object enters into atemporal relations (e.g. prepositional "inclusion") with other conceptualized objects (e.g. "the gray shark at the beach"), and so on recursively.

Note that the basic perceptual "qualities" shared by basic level objects the property that their status as conceptualizations emerges from a participatory relation between the human conceptual system and the world, such that it is likely that human conceptualizers will 
constitute conceptualizations (e.g. "colors") out of the spectral continuum in similar ways across cultures and put these conceptualizations in similar relations to other conceptualizations to generate more complex conceptualizations (Martin 2011). In this respect the number of conceptualizations that are available to be generated from the usual perceptual qualities are not open ended. Instead the human conceptual system seems to generate a fairly manageable number of these qualities in schematic forms which are then used in conceptual combinations with other conceptualizations in a given culture. That said, via the metaphorical mapping, recombination, and "blends" of such basic conceptualizations persons can generate an essentially open-ended number of cultural elements (Fauconnier and Turner 2008; Lakoff 1987).

\section{Dynamic Cultural Causal Systems}

We are now in a position to further consider the proper unit of cultural analysis from an analytic perspective, this is the dynamic cultural causal system (DCCS). A DCCS is both a cultural system composed of the cultural units and relations between units, at different levels of constituency, internalized in persons and distributed across persons and a causal system featuring two-way cause-effect relations between cultural units---as internalized and externalized by persons---and other components of the interactive context. In this respect, a DCCS has four obligatory component parts: (a) a set of persons, (b) a set of cultural units (and cultural relations) internalized by persons as part of their enculturation history, (c) a set of social relations between persons, and (d) a set of "externalized" elements that link up to the culture internalized by persons, such as cultural symbols and material artifacts. These last are particularly important, in their role as mediators of processes cultural expression, transmission, and construction in the interactive context in question.

Most cultural analysts are interested in what could be referred to as "meta-phenomena" the most important of which are cultural invention or genesis, reproduction, and change, for instance, from one settled state to the next (Archer 1996). 
Most of the specific phenomena dealt with in substantive studies are exemplifications of one of these three categories. A "settled" state of a given DCCS may be instantiated in a given distribution of cultural units and cultural relations within and across persons, as well as associated arrangement of social relations, cultural artifacts, and cultural symbols.

A key point for our purposes, is that genesis, reproduction, and change happen within DCCSs. In cultural analysis, the key focus is on the so-called "endogenous" mechanisms that help to generate these phenomena (Kaufman 2004) These mechanisms are endogenous because they deal with the "internal" relations between cultural elements. There are four ideal-typical endogeneous cultural mechanisms involved in generating interesting phenomena. These are (1) Cultural recombination (construction) mechanisms, (2) cultural acquisition (learning) mechanisms, (3) cultural remembering (reconstruction) mechanisms, and (4) cultural communication (transmission) mechanisms.

In general, the four endogenous cultural mechanisms operate as couplets or even triples, so that most interesting phenomena are generated via the concatenation of multiple endogenous processes. For instance, the generation of novel cultural units (e.g. new baby names (Lieberson 2000)) recruits a meaning construction (recombination) process, whereby (a) parent(s) uses bits of the extant cultural heritage (the set of names, and most important the syllabic components of such names, with which they are familiar given previous "upstream" processes of cultural transmission, learning, and remembering). The parent may then generate a new name by recombining syllabic elements using constructional principles typical of their local milieu or familiar to them via their social relations with other persons. For instance, in Louisiana the French-origin prefix "Le" or "La" is equivalent to the English "the" and can be affixed to other "standard" names so that they form a new "well-formed" gestalt (e.g. "LaQuan"). This new cultural object then is subject to downstream processes of transmission, encoding, reconstruction, and further recombination and extension productive of further cultural change ("LaQuinton") or stasis (more children name LaQuan).

\subsection{Cultural Change in Dynamic Cultural Causal Systems}


Cultural change happens when people use extant cultural units to generate novel combinations of such units. This endogenous mechanism is the primary one implicated in cultural change and cultural genesis episodes (Clemens and Cook 1999; Rao, Monin, and Durand 2005). While not usually noted, the very idea of recombination (or "bricolage") as an endogeneous cultural mechanism implies a view of culture of the sort espoused above (e.g. cultural units having compositional or part-whole relations). Most institutional domains are composed of such units. For instance, in the world of cuisine a "dish" or "recipe" as a (conceptualized) cultural unit is itself composed of lower order cultural units (e.g. ingredients) which are combined according to established "constructional" rules to generate a well-formed gestalt (Leschziner 2015). Sets of cultural units sharing common parts (e.g. ingredients) and constructional rules, may thus be grouped together to form meta-units which are conceptualized as such by a given set of experts ("cuisines" or "gastronomic styles"). In fields that are organized around the production of such cultural units, cultural change is instigated by producers who "break the rules" by recombining lower level cultural units in unexpected ways (Rao, Monin, and Durand 2005). This can be done either by the introduction of novel parts (e.g. ingredients) within the same set of constructional rules for putting them together, or (more decisively) by changing the constructional rules themselves. In this case, analysts speak of an episode of cultural or institutional change proper (Clemens and Cook 1999).

The recombination mechanism schema is of quite general applicability. It applies to language as a cultural meta-unit itself (where the elements are the lexicon and the morphemic and syllabic components of the lexicon) and the constructional "rules" are the set of standing (sanctioned) constructions in the "grammar" of the language at that time. As noted above, it applies to baby names, recipes, and as other research shows it applies to essentially any formal or informal domain of cultural production and reproduction. An important observation is that recombination does not necessarily lead to radical change or rupture. For the most part, most recombination is conservative and only generates spurious 
novelty as it consists of taking elements from a sanctioned set and combining them together using an equally sanctioned set of constructional rules (Lieberson 2000).

Changing the rules of the game, either by bringing in new elements or changing the rules may be subject to processes of social control by ostracizing the producers of such new combinations or delegitimizing the resulting products (Bourdieu 1993). Novelty in this sense, may sometimes require embedding the recombination mechanisms within an interactional context in which novelty is protected from this sort negative reception. In the case of "Black names" in the U.S. (Lieberson 2000), one of the most significant recent cultural innovations, this interactional context was one of social segmentation as a result of segregation, which protected some Black families from the sort of social sanctioning to cultural innovation they would have received had they lived in interactional contexts dominated by Whites. In some cases, most radical forms of cultural change require the introduction of "exogenous" shocks (e.g. war, political or social revolution) into the endogeneous functioning of DCCSs (Fishman and Lizardo 2013; Obukhova, Zuckerman, and Zhang 2014).

\section{Conclusion}

In this paper, I have outlined a general framework for cultural analysis that is generally consistent with an "analytic" approach to explanation in science (Hedstrom 2005; Bunge 1997). Consistent with the general tenets of this approach this framework emphasizes the identification and specification of cultural phenomena within concrete interactive systems. In contrast to the unmoored, ontologically suspect "holistic" systems of classic organicist functionalism and semiotic structuralism, these dynamic cultural causal systems are subject to the heuristic discovery strategies of localization and decomposition. Thus, from an analytic perspective culture is always located somewhere (most directly in persons and indirectly in their relations and artifacts), and every cultural phenomenon is always decomposable into its lower level component units. Decomposition, as noted above, does not imply reduction, as DCCSs allow for emergence of higher level phenomena from the 
interaction of persons, their relations, and processes of recombination, transmission, learning, and memory.

Most of the argumentation here has been negative (of the "clearing ground" variety) as a key problem in cultural analysis in relation to emerging "analytic" and "mechanismic" perspectives across the sciences is the residual allegiance to (usually "folk") conceptualizations of culture that resist the heuristic goals of localization ("where is culture?") and decomposition ("what is culture made out of?"). Thus, making cultural theory compatible with an analytic approach necessitates taking "bright line" stances on issues (such as the "neuro-cognitive" nature of culture and the specification of "cultural units") that most cultural analysts prefer to endlessly equivocate on. Here I show that such an approach can be useful for handling most of the "meta-phenomena" of interest to cultural analysts, inclusive of the most important one of all, which is concerned with processes of cultural genesis and change. 


\section{References}

Alexander, Jeffrey. 1992. “The Promise of a Cultural Sociology.” Theory of Culture. Berkeley: University of California Press, 293-323.

Alexander, Jeffrey C. 2003. The Meanings of Social Life: A Cultural Sociology. New York: Oxford University Press. Anderson, Michael L. 2014. After Phrenology: Neural Reuse and the Interactive Brain. MIT Press.

Archer, M. S. 1996. Culture and Agency: The Place of Culture in Social Theory. Cambridge University Press.

Barrett, J. L. 2000. "Exploring the Natural Foundations of Religion.” Trends in Cognitive Sciences 4 (1): 29-34.

Barsalou, Lawrence. 2003. "Situated Simulation in the Human Conceptual System." Language and Cognitive Processes 18 (5-6): 513-62.

Barsalou, Lawrence W. 1992. Frames, Concepts, and Conceptual Fields. Lawrence Erlbaum Associates, Inc.

Bechtel, William, and Adele Abrahamsen. 2005. "Explanation: A Mechanist Alternative." Studies in History and Philosophy of Biological and Biomedical Sciences 36 (2): 421-41.

Bechtel, William, and Robert C. Richardson. 2010. Discovering Complexity: Decomposition and Localization as Strategies in Scientific Research. MIT Press.

Berger, Peter L., and Thomas Luckmann. 1966. The Social Construction of Reality: A Treatise in the Sociology of Knowledge. Anchor Books. New York: Doubleday.

Biernacki, Richard. 2000. "Language and the Shift from Signs to Practices in Cultural Inquiry." History and Theory 39 (3). Blackwell Publishers Inc.: 289-310.

Bloch, M. 2012. Anthropology and the Cognitive Challenge. Anthropology and the Cognitive Challenge. Cambridge University Press.

Bloch, Maurice. 1986. "From Cognition to Ideology." In Knowledge and Power: Anthropological and Sociological Approaches, edited by R. Fardon, 21-48. Edinburgh: Scottish University Press.

Bourdieu, Pierre. 1993. The Field of Cultural Production: Essays on Art and Literature. New York: Columbia University Press.

Bunge, Mario. 1997. "Mechanism and Explanation." Philosophy of the Social Sciences 27 (4). SAGE Publications: 410-65.

- 2004. "Clarifying Some Misunderstandings about Social Systems and Their Mechanisms." Philosophy of the Social Sciences 34 (3). SAGE Publications: 371-81.

Clemens, Elisabeth S., and James M. Cook. 1999. "POLITICS AND INSTITUTIONALISM: Explaining Durability and Change." Annual Review of Sociology 25 (1). Annual Reviews: 441-66.

Cohen, Dov, and Angela K-Y Leung. 2009. "The Hard Embodiment of Culture." European Journal of Social Psychology 39 (7). John Wiley \& Sons, Ltd.: 1278-89.

Coulson, Seana. 2001. Semantic Leaps: Frame-Shifting and Conceptual Blending in Meaning Construction. Cambridge University Press.

D'andrade, Roy. 2001. "A Cognitivist's View of the Units Debate in Cultural Anthropology." Cross-Cultural Research 35 (2): 242-57.

DiMaggio, Paul. 1997. "Culture and Cognition." Annual Review of Sociology 23. Annual Reviews: 263-87.

Elder-Vass, Dave. 2007. "For Emergence: Refining Archer's Account of Social Structure." Journal for the Theory of Social Behaviour 37 (1). Blackwell Publishing Ltd: 25-44.

- 2012. The Reality of Social Construction. Cambridge University Press.

Fauconnier, Gilles, and Mark Turner. 2008. The Way We Think: Conceptual Blending And The Mind's Hidden Complexities. Basic Books.

Fine, Gary Alan. 1979. "Small Groups and Culture Creation: The Idioculture of Little League Baseball Teams.” American Sociological Review 44 (5). [American Sociological Association, Sage Publications, Inc.]: 
733-45.

Fishman, Robert M., and Omar Lizardo. 2013. "How Macro-Historical Change Shapes Cultural Taste: Legacies of Democratization in Spain and Portugal." American Sociological Review 78 (2). Sage Publications Sage CA: Los Angeles, CA: 213-39.

Gatewood, John B. 2001. "Reflections on the Nature of Cultural Distributions and the Units of Culture Problem." Cross-Cultural Research: Official Journal of the Society for Cross-Cultural Research / Sponsored by the Human Relations Area Files, Inc 35 (2). Sage Publications: 227-41.

Geertz, Clifford. 1973. The Interpretation of Cultures: Selected Essays. New York: Basic books.

Ghaziani, Amin. 2009. "An 'amorphous Mist'? The Problem of Measurement in the Study of Culture." Theory and Society 38 (6). Springer Netherlands: 581-612.

Giddens, A. 1979. Central Problems in Social Theory: Action, Structure, and Contradiction in Social Analysis. Campus Berkeley. University of California Press.

Goddard, Cliff. 2005/1. “The Lexical Semantics of Culture.” Language Sciences 27 (1): 51-73.

Hays, Sharon. 1994. "Structure and Agency and the Sticky Problem of Culture." Sociological Theory 12 (1).

[American Sociological Association, Wiley, Sage Publications, Inc.]: 57-72.

Hedstrom, P. 2005. Dissecting the Social: On the Principles of Analytical Sociology. Cambridge University Press.

Hedström, Peter, and Petri Ylikoski. 2010. "Causal Mechanisms in the Social Sciences." Annual Review of Sociology 36 (1). Annual Reviews: 49-67.

Hjelmslev, Louis. 1961. Prolegomena to a Theory of Language. Translated by Francis J. Whitfield. University of Wisconsin Press.

Hutchins, Edwin. 1995. Cognition in the Wild. Cambridge, MA: MIT Press.

Ignatow, Gabe. 2014. "Ontology and Method in Cognitive Sociology." Sociological Forum 29 (4): 990-94.

Jepperson, R., and J. W. Meyer. 2011. "Multiple Levels of Analysis and the Limitations of Methodological Individualisms." Sociological Theory. Wiley Online Library.

http://onlinelibrary.wiley.com/doi/10.1111/j.1467-9558.2010.01387.x/full.

Johnson, M. 2013. The Body in the Mind: The Bodily Basis of Meaning, Imagination, and Reason. University of Chicago Press.

Kaufman, Jason. 2004. "Endogenous Explanation in the Sociology of Culture." Annual Review of Sociology 30 (1). Annual Reviews: 335-57.

Kitayama, Shinobu. 2002. "Culture and Basic Psychological Processes--toward a System View of Culture: Comment on Oyserman et Al. (2002).” Psychological Bulletin 128 (1): 89-96.

Kövecses, Zoltán. 2003. Metaphor and Emotion: Language, Culture, and Body in Human Feeling. Cambridge University Press.

Kuper, Adam. 2009. Culture: The Anthropologists' Account. Harvard University Press.

Lakoff, George. 1987. "Women, Fire and Dangerous Things: What Concepts Reveal about the Mind." Chicago University Press.

- 1993. "The Contemporary Theory of Metaphor." In Metaphor and Thought, edited by A. Ortony, Second, 202-51. Cambridge, UK: Cambridge: University Press.

Langacker, Ronald W. 1987. Foundations of Cognitive Grammar: Theoretical Prerequisites. Stanford University Press. Leschziner, Vanina. 2015. At the Chef's Table: Culinary Creativity in Elite Restaurants. Stanford University Press. Lieberson, Stanley. 2000. A Matter of Taste: How Names, Fashions, and Culture Change. Yale University Press. Lizardo, Omar. 2013. "Re-Conceptualizing Abstract Conceptualization in Social Theory: The Case of the 'Structure' Concept.” Journal for the Theory of Social Behaviour 43 (2). Wiley Online Library: 155-80.

— 2016a. "Cultural Theory." In Handbook of Contemporary Sociological Theory, edited by Seth Abrutyn, 99-120. Springer International Publishing,.

—_. 2016b. "Cultural Symbols and Cultural Power." Qualitative Sociology 39 (2). Springer US: 199-204.

- 2017. "Improving Cultural Analysis: Considering Personal Culture in Its Declarative and Nondeclarative Modes." American Sociological Review. SAGE Publications Sage CA: Los Angeles, CA, 
0003122416675175.

Machamer, Peter, Lindley Darden, and Carl F. Craver. 2000. “Thinking about Mechanisms.” Philosophy of Science 67 (1): 1-25.

Martin, John Levi. 2011. The Explanation of Social Action. Oxford University Press.

McCauley, Robert N., and William Bechtel. 2001. "Explanatory Pluralism and Heuristic Identity Theory." Theory \& Psychology 11 (6). Sage Publications: 736-60.

Nosek, Brian, M. R. Banaji, and A. G. Greenwald. 2010. "Project Implicit." Retrieved from bttpsV/implicit. Harvard. Edu/ implicit.

Obukhova, Elena, Ezra W. Zuckerman, and Jiayin Zhang. 2014. "When Politics Froze Fashion: The Effect of the Cultural Revolution on Naming in Beijing." The American Journal of Sociology 120 (2): 555-83.

Parsons, Talcott. 1938. "The Role of Ideas in Social Action." American Sociological Review 3 (5). [American Sociological Association, Sage Publications, Inc.]: 652-64.

- 1951. The Social System. Glencoe, Illinois: The Free Press,.

Patterson, Orlando. 2014. "Making Sense of Culture." Annual Review of Sociology 40 (1): 1-30.

Rao, Hayagreeva, Philippe Monin, and Rodolphe Durand. 2005. "Border Crossing: Bricolage and the Erosion of Categorical Boundaries in French Gastronomy." American Sociological Review 70 (6): 968-91.

Reay, Mike. 2010. "Knowledge Distribution, Embodiment, and Insulation*." Sociological Theory 28 (1). Blackwell Publishing Inc: 91-107.

Reed, Isaac Ariail. 2011. Interpretation and Social Knowledge: On the Use of Theory in the Human Sciences. Chicago: University of Chicago Press.

Saussure, Ferdinand de. 1964. Course in General Linguistics. Edited by F, C. Bally, and A. Sechehaye. Translated by Roy Harris. Chicago: Open Court.

Schröder, Tobias, and Paul Thagard. 2013. "The Affective Meanings of Automatic Social Behaviors: Three Mechanisms That Explain Priming." Psychological Review 120 (1): 255-80.

Searle, John R. 1995. The Construction of Social Reality. New York: Free Press.

Sewell, William H., Jr. 2005. “The Concept (s) of Culture.” Practicing History: New Directions in Historical Writing after the Linguistic Turn. Routledge New York, NY, 76-95.

Smith, Christian. 2011. What Is a Person?: Rethinking Humanity, Social Life, and the Moral Good from the Person Up. University of Chicago Press.

Sperber, Dan. 1996. Explaining Culture: A Naturalistic Approach. Wiley.

Strauss, Claudia, and Naomi Quinn. 1997. A Cognitive Theory of Cultural Meaning. Vol. 9. Cambridge University Press.

Swidler, Ann. 2000. "Cultural Power and Social Movements." In Culture and Politics, edited by Lane Crothers and Charles Lockhart, 269-83. Palgrave Macmillan US.

- 2001. "What Anchors Cultural Practices." In The Practice Turn in Contemporary Theory, edited by Karin Knorr Cetina, Theodore R. Schatzki, and Eike von Savigny, 74-92. London: Routledge.

Thagard, Paul. 2014. "The Self as a System of Multilevel Interacting Mechanisms." Philosophical Psychology 27 (2). Routledge: 145-63.

Varela, Charles R., and Rom Harré. 1996. "Conflicting Varieties of Realism: Causal Powers and the Problems of Social Structure." Journal for the Theory of Social Behaviour 26 (3). Blackwell Publishing Ltd: 313-25.

Wierzbicka, A. 1992. Semantics, Culture, and Cognition: Universal Human Concepts in Culture-Specific Configurations. Oxford University Press.

Woodward, James F. 2011. “Data and Phenomena: A Restatement and Defense.” Synthese 182 (1). Springer Netherlands: $165-79$. 